\title{
Mentoring and Coaching as a Learning Technique in Higher Education: The Impact of Learning Context on Student Engagement in Online Learning
}

\author{
Kelum A. A. Gamage ${ }^{1, *(D)}$, D. A. Sharmini Perera ${ }^{2}$ and M. A. Dilini N. Wijewardena ${ }^{2}(\mathbb{D}$ \\ 1 Centre for Educational Development and Innovation, James Watt School of Engineering, \\ University of Glasgow, Glasgow G12 8QQ, UK \\ 2 Business School, Sri Lanka Technological Campus, Padukka 10500, Sri Lanka; sharminip@sltc.ac.lk (D.A.S.P.); \\ diliniw@sltc.ac.lk (M.A.D.N.W.) \\ * Correspondence: Kelum.Gamage@glasgow.ac.uk
}

check for updates

Citation: Gamage, K.A.A.; Perera, D.A.S.; Wijewardena, M.A.D.N

Mentoring and Coaching as a Learning Technique in Higher Education: The Impact of Learning Context on Student Engagement in Online Learning. Educ. Sci. 2021, 11, 574. https://doi.org/10.3390/ educsci11100574

Academic Editor: Han Reichgelt

Received: 12 August 2021

Accepted: 17 September 2021

Published: 23 September 2021

Publisher's Note: MDPI stays neutral with regard to jurisdictional claims in published maps and institutional affiliations.

Copyright: (c) 2021 by the authors. Licensee MDPI, Basel, Switzerland. This article is an open access article distributed under the terms and conditions of the Creative Commons Attribution (CC BY) license (https:/ / creativecommons.org/licenses/by/ $4.0 /)$.

\begin{abstract}
Coaching and mentoring has been regarded as one of the key learning techniques in the modern learning environment in the recent past. With the swift shift in the higher education sector to a more digitally driven learning environment, limited research has evaluated the impact of coaching and mentoring on student engagement in online learning. This study aimed to evaluate the impact of coaching and mentoring on enhancing student engagement in the higher education sector. The study applied a combination of quantitative and qualitative methods of data collection, where the primary data were collected from 120 respondents via a questionnaire and 20 in-depth interviews, covering undergraduates through a simple random sampling technique. The data analysis showed that the mentor's ability to facilitate learning and encourage mentees to be focused on their goals were the most significant factors that affected student engagement in online learning. In total, $43 \%$ of the respondents extremely agreed that they are willing to recommend their colleagues to receive the service of a mentor to help them reach their optimum potential in an online learning environment. The findings of the study recommend that the higher educational institutes should administer a sound mentoring process that meets the ethical backgrounds to consistently support the continuous improvement of the students in an online learning environment to enhance their engagement in learning activities.
\end{abstract}

Keywords: coaching; mentoring; higher education; online learning environment; student engagement

\section{Introduction}

The rapid changes in higher education with online delivery and an increase in the use of technology has made it more challenging to ensure student engagement and professorial development. Consequently, students in the higher education sector are encouraged to engage and participate actively in their learning process as well as be goal-oriented in understanding their future desires, which will help them to work towards achieving their goals, even in a turbulent environment. Conversely, as per the Future Jobs Report presented by the World Economic Forum, re-skilling of at least $50 \%$ of the workforce is required by 2025 in the digitally driven world, more than ever before. This leads to an escalated need for skills, such as critical thinking and problem-solving. Furthermore, skills in selfmanagement through active learning, resilience, stress tolerance, and flexibility are given utmost importance with the impact of COVID 19 and the changes that took place in the environment in the year 2020 [1]. Thus, these skills must be developed continuously through the higher education system to meet the needs of the local and global industries in an ever-changing environment. Coaching and mentoring helps to encourage, challenge, and motivate coaches/mentees to be focused on their specific goals, setting up action plans, and implementing the plan of actions with more self-discipline. Hence, this contributes 
to the development of self-management skills, self-learning, and identifying, as well as reaching one's own optimum potential.

The impact of coaching and mentoring as a learning technique has been researched in the recent past to a considerable level. However, limited research has studied its impact on student engagement in higher education in a digitally driven learning environment. This study aimed to understand the contribution of coaching and mentoring in creating an environment for student engagement that enables them to be goal oriented to uplift their skills that are required in the future workplace.

\section{Review of Literature}

Mentoring is primarily concerned with identifying and fostering a person's potential as a whole [2]. It can be a long-term partnership in which the learner sets the goals, which may alter over time. Both the goals and the process belong to the learner and the mentor helps the mentee gain insight and knowledge by assisting them in being more conscious of their own experiences through intrinsic observation. Coaching is largely concerned with improving performance in a certain skill area, typically in the short term. The coach usually sets the goals, or at least the intermediate or sub-goals, with or at his recommendation, while the student is in charge of the objective and the teacher is in charge of the execution [3].

Mentoring and coaching encourage the development of a professional and personal relationship that benefits persons to obtain skills required to be relevant and competitive in the academic world, especially in higher education [4]. Higher education institutions (HEIs) are gradually identifying the importance and effects of coaching for professional and organizational development [5,6]. Positive effects of coaching and mentoring in HEIs have been reported based on semi-structured interviews and focus group discussions. They suggest the advantages of training internal coaches and further emphasize the effectiveness of facilitating personal and professional development and its contribution to organizational goals being achieved. The studies on the capabilities of active listening identified that it can inspire people to take responsibility for their own work and it encourages the development of critical thinking abilities in problem solving.

Several studies have been carried out successfully for coaching approaches $[7,8]$ and found that if coaching remains on an individual level, improvement in the school sector will be unsuccessful. Applying one-to-one coaching interferences for educational leaders, teaching staff, and students, coaching cultures can be implemented effectively in educational settings [9].

Academic coaching can be effectively used for college students who are academically at risk. It has been explored [10] through the Academic Coaching for Excellence (ACE) program and the results suggest that these programs can have a significant impact on students' academic performance and retention. The intervention is effective in improving overall academic performance, pushing students toward degree completion, and encouraging academically at-risk students to stay in school. Furthermore, studies show [11] the significance of having a tutoring, coaching, and mentoring system in place to boost student retention and help them improve their academic and learning performance, as well as to assist teachers in receiving accurate feedback to improve their teaching process. These studies emphasize the significance of putting in place a system that uses coaching, mentoring, and tutoring to help students in higher education attain greater levels of learning.

According to the findings of [12], opportunities for professional development, academic confidence, broadened thinking, promotion of a collaborative atmosphere, and the significance of goal setting in academia have all been found to have a beneficial influence on the mentee. Based on these beneficial outcomes, it has been proposed that mentoring is an essential activity that should be encouraged in higher education through frameworks that are specific to each setting. Reflective analysis was conducted in response to the research question, 'How can academic mentoring/coaching impact the professional development of a mentee?'. Five primary themes concerning the impact of educational 
mentoring and training on the professional development of a mentee were found. Career progression and broadened thinking, enhanced intellectual confidence, collaborative working, skills development, and goal setting and action planning were included among the topics.

Knippelmeyer and Torraco [13] presented a theoretical model for mentoring in higher education, which depicts higher education as a context in which informal learning may be reconceptualized as mentoring for junior teachers. They have studied and explored literature relevant to faculty mentoring programs in higher education in order to develop this proposal, stressing the relevance and advantages of mentoring in higher education [14]. They also addressed how higher education institutions may help establish mentorship programs and how they can be conducted successfully using the notion of informal or accidental learning. Later, they reached the conclusion that organizations may learn to overcome the hurdles to mentoring relationships and implement programs into their daily work routines that would help them succeed in the future. Once mentorship has taken place and the protégés have realized the real worth of the growth that occurs within the mentor-protégé relationship, they can pass on their mentoring knowledge and experience to someone else rising through the ranks of academics, resulting in a continuous cycle.

In a study of the determinants of high-quality and effective mentorship among academic staff in a Ghanaian public research university [15], it was identified that institutional career assistance, assistance from senior faculty, and support from peers all influence academic mentorship in the University of Ghana, which further reflects the higher education system in a developing country. Correspondingly, the data suggest that management and coworker support would have a favorable influence on the professional responsibilities and lifestyles of junior and rookie academic staff, resulting in higher academic quality. In higher education institutions, good social interaction among co-workers and between management and workers will lead to successful faculty engagement and between faculty and their university. Furthermore, the data show that healthy social interaction among academics leads to effective cooperation and information sharing in the form of coworker mentorship and institutional support. As a result, universities in developing nations might enlist the help and expertise of senior or experienced faculty or faculty members in the form of mentoring in order to boost their institutions' exposure or competitive advantage. Similarly, these findings would also lead to our intension 'Mentoring and Coaching as a Learning Technique in Higher Education', mainly based on the efficacy of student coaching and mentoring.

Thus, previous studies indicate the significant importance of coaching and mentoring in higher education. Furthermore, online learning is a relatively new social activity that is increasingly being used to replace both distance learning and traditional face-to-face classes [16-19]). This has been a considerable change in higher education due to the Covid-19 pandemic, which is also considered in our research as shifting to online learning has been a challenge for many students who are used to learning in physical classrooms [20].

\section{Methodology}

The research question that is being addressed in this study is "What is the impact of coaching and mentoring on students' engagement during online learning?" with the hypothesis regarding the relationship of coaching and mentoring with students' engagement in online learning. Both quantitative and qualitative methods were adopted. Primary data were collected through a self-administered questionnaire that was distributed among 150 undergraduates from third year first semester, covering five different disciplines: engineering, management, technology, computing and information technology, and music in Sri Lanka Technological Campus who were hoping to enter an internship program. A sample size of 120 duly filled questionnaires were collected online. The sampling technique was simple random sampling where out of the population of undergraduates who received the service of their academic mentors through individual and group mentoring sessions were drawn into the sample within a period of three months in the year 2020 during their 
first fully delivered online learning semester. Quantitative analysis was done with these collected questionnaire data. Furthermore, to support the findings of the quantitative analysis, 20 in-depth interviews were carried out within the said sample via an online mode, which were qualitatively analyzed. A Likert scale of 1 to 5 was used in collecting the data in the questionnaire, where 1 indicated extremely disagree and 5 indicated extremely agree with the given statements. A descriptive analysis of the quantitative data was done along with the regression with the use of SPSS version 20.

\section{Results}

Out of the sample, $61 \%$ were male respondents and $39 \%$ were female respondents. Regarding respondents' understanding of the clarity of the purpose of the mentoring sessions that they attended, $53 \%$ of the respondents extremely agreed that the purpose was very clear to them and 33\% agreed. The next set of questions inquired about their opinion on the helpfulness of the sessions to re-look at the areas of concern that they need to work on enhancing their engagement in learning. In total, $50 \%$ of the respondents extremely agreed that the sessions helped to enhance their engagement in learning while $44 \%$ agreed. In total, $60 \%$ of the respondents extremely agreed that their sessions with the mentors and coaches were well designed and organized and the content of the discussion was clear to them while $27 \%$ agreed. Regarding the adequate support provided by the mentors to facilitate learning and the sessions helped the mentees to be more focused towards their learning process, $47 \%$ of the respondents extremely agreed while $46 \%$ agreed. In total, $57 \%$ of the respondents extremely agreed with the fact that the mentors encouraged them to think beyond their comfort zones and it helped to realize their areas of improvement in an online learning environment while $30 \%$ agreed. Furthermore, $40 \%$ of the respondents extremely agreed that the mentoring session helped them to realize their true potential and self-management techniques to be focused on their learning activities in the online learning environment while $44 \%$ agreed. When asked about the impact of continuous feedback and follow-up sessions, $44 \%$ extremely agreed that the continuous feedback and follow-up sessions with the mentors encouraged them in working on their action plans and accomplishing their intended academic and personal achievements and $42 \%$ agreed with the given statements. In total, $40 \%$ extremely agreed that the mentoring sessions helped them to be focused on their life goals and to enhance their capabilities in skill development, such as critical thinking and problem-solving, especially in an online learning environment, whereas $50 \%$ agreed. Moreover, $43 \%$ extremely agreed that they would recommend their colleagues to receive the service of a coach or a mentor for self-development and enhance engagement in their academic life. These findings are shown in Figure 1.

The regression analysis depicts an adjusted $\mathrm{R}$ square of $83 \%$, indicating a good model fit between the variables. The conceptual model tested the relationship of the independent variables namely the purpose of the mentoring program, organization, and content of the mentoring sessions; facilitation method of the mentor; mentor's ability to encourage; mentor's communication method; and mentor's knowledge on the impact of enhancing the mentee's engagement in being focused on academic goals. These kinds of conceptual models with independent variables have been used in previous research related to coaching and mentoring $[3,21]$. The $p$-value $(p)$ in the regression depicts the significant level and if it is less than 0.05 , it indicates that the independent variable has a significant impact on the dependent variable. On the other hand, the Beta $(\beta)$ value depicts whether the relationship is positive or negative between the independent and dependent variable as well as the variable that has the most significant impact on the dependent. As per the regression co-efficient analysis of this study, the mentor's ability to provide adequate support to facilitate learning and the ability to encourage $(p=0.05)$ were the most significant factors that had a positive ( $\beta=0.374)$ impact to enhance the mentee's learning engagement. 


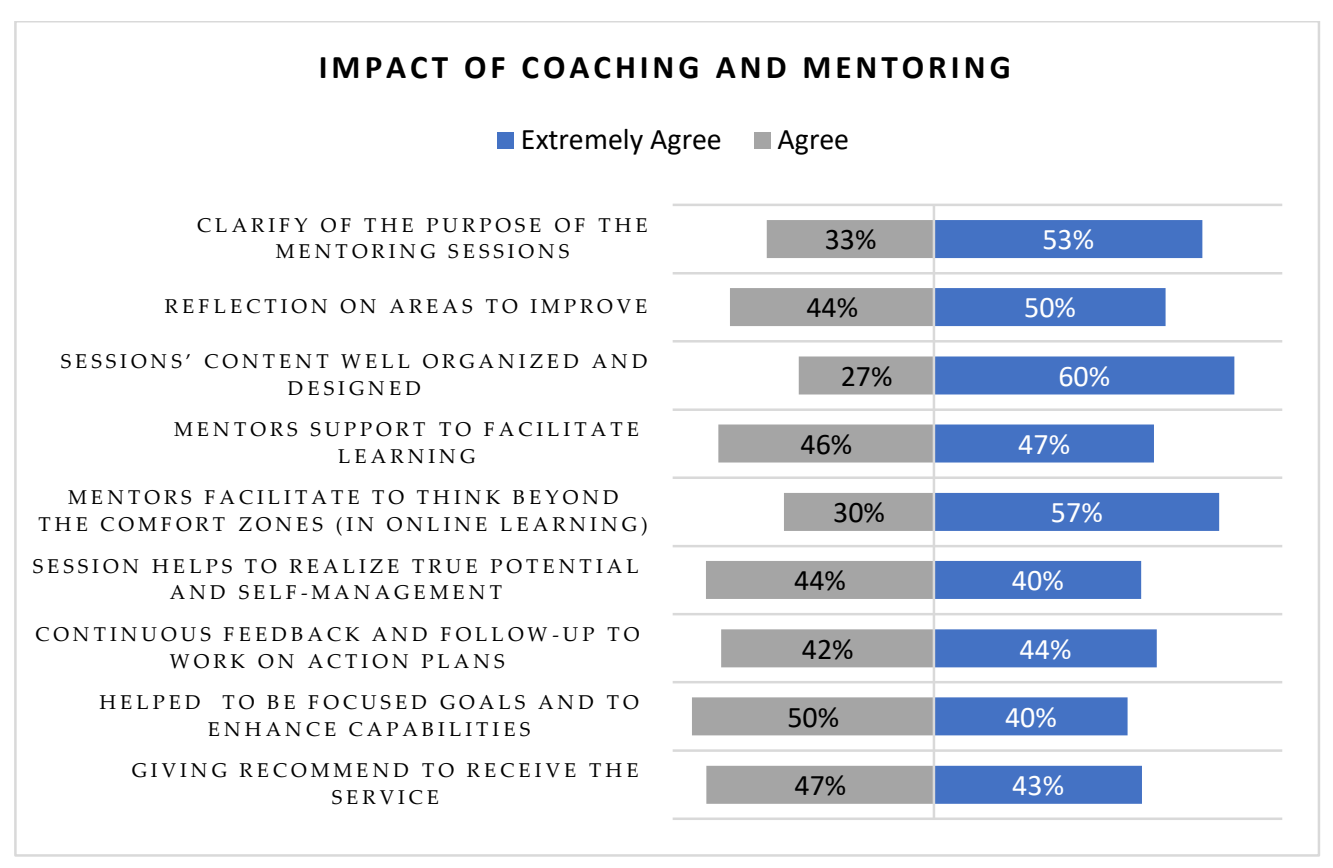

Figure 1. Analysis of the impact of coaching and mentoring.

Furthermore, the regression analysis on the relationship between the above-mentioned independent variables and its impact on the mentee's intention to recommend the mentoring process to their colleagues indicated an $\mathrm{R}$ square value of $70 \%$, confirming the good fit of the model. The mentor's ability to encourage the mentee to think beyond one's comfort zone $(p=0.032)$ and the knowledge/information gained through the mentoring session $(p=0.004)$ were shown as the most significant factors as per the co-efficient results that have an impact on the mentee's willingness to recommend the mentoring services to their colleagues. These quantitative results imply that mentoring in higher education institutes creates a positive impact in students' learning and development.

The findings of the in-depth interviews supported the quantitative data analysis where the respondents indicated that their personal commitment to online learning, taking part in assessments, finding their true potential, and most of all understanding their own personalities enabled them to enhance their engagement and find new methods of learning to be focused towards their academic goals. Furthermore, the findings from the interviews indicated that the on-time submissions of assessments, satisfactory grading earned for assessments, and increased grading in their academic performances were evident with the personal effort made due to the support and encouragement received by their mentors and coaches. These findings are aligned with previous research indicating that effective mentoring enhances student learning and development [22]. Thus, the qualitative survey results show that mentoring and coaching would be a positive influence for students in their learning and professional development.

Furthermore, being able to develop a mentor-mentee relationship was mentioned as an important element in the mentoring process for enhanced engagement. A respondent mentioned: "it is indeed a good way to become closer to the faculty and if the method of mentoring is undertaken in the delivery process it would encourage more active participation of the students with interactive delivery even in the online learning". Another commented: "online learning may at times be hectic due to many technical issues faced, however through the mentoring sessions it helped me to find alternative methods of learning and speak to my lecturers for additional support required". This indicated that the mentor was able to continuously encourage and motivate the student to find solutions to the problems faced in online learning and still be focused on the outcome. It is also supported by the comment of another respondent that the mentoring helped her to over- 
come her psychological fears and anxiety of not being able to adapt to online learning: "I once suffered from depression where I was under medication and was able to recover. However, with the change to a complete online learning environment due to the pandemic, I experienced anxiety and was in fear that I may not be able to adjust. These mentoring sessions helped me to look at my life with a clear vision, to manage my emotions and to be focused on my academic and non-academic activities". This mentor-mentee relationship was a real support to the students as they suffered from various difficulties, such as a lack of self-confidence, not having a clear idea of how to achieve his/her goals in the competitive environment, how to manage their work-load, family problems, etc., and these problems were much more significant with the online learning environment. Therefore, it is a good approach to having coaching and mentoring as a learning technique to uplift students academic and professional development.

\section{Discussion}

As per the findings of the research, regression analysis reveals a fine relationship between the independent variables: the purpose of the mentoring program, organization and content of the mentoring sessions, facilitation method of the mentor, mentor's ability to encourage, mentor's communication method, and mentor's knowledge on the impact of enhancing the mentee's engagement in being focused towards academic goals and also the impact of these independent variables on the dependent variable. These analysis results are supported by previous research findings related to various fields [23-25]), emphasizing the validity as well as the uniqueness of our research. Thus, this research area can be used as a model by decision makers and policy makers to use coaching and mentoring in their organizations.

As found in the results, the most significant factors of mentoring are the mentor's capacity to give appropriate assistance to enable learning and the ability to encourage. These important characteristics encourage the decision makers for practicing coaching and mentoring as a skill for providing encouragement and alternative support to the mentees. There are also related findings regarding this kind of regression analysis that support our results $[15,26,27]$.

Furthermore, as supported by the qualitative and quantitative data analysis, coaching and mentoring support $[28,29]$ can be used for building professional development in persons who are influenced by coaching and mentoring. In our research, as students are engaged in online learning for a semester for the very first time in their lives, this support and encouragement has been a real motivation for their academic and personal development and mental stability. Based on the results and discussion, the following conclusions and recommendations can be gained.

\section{Conclusions and Recommendation}

The findings demonstrate that taking part in mentoring and coaching is beneficial to the undergraduates in terms of their academic engagement and that the effort spent in being mentored or coached enhanced their confidence level and capabilities. Students whose mentors provided an environment to explore individual strengths and capabilities reported stronger learning and development. The study indicates that mentorship programs would pave the path for desirable higher education student engagement in the online learning environment. Thus, it is recommended that the higher educational institutes activate a sound and reliable mentoring program where each student is allocated with a mentor from the inception of joining the institute. Especially in an online learning environment, a mentor is recommended to be given access to the academic performance data of his/her mentees and the mentoring session to be conducted in a scheduled as well as a systematic manner to provide continuous feedback and encouragement to the mentee. This study is in general aimed at the impact of mentoring on student engagement in online learning. However, it is recommended that future research may focus on the impact of mentor skills and trust on student engagement in online learning and it will provide more in- 
depth findings on the skills that a mentor must develop for effective mentoring to suit online learning.

Author Contributions: Conceptualization, D.A.S.P. and K.A.A.G.; methodology: K.A.A.G.; formal analysis, M.A.D.N.W. and D.A.S.P.; investigation, D.A.S.P. and M.A.D.N.W.; resources, K.A.A.G.; data collection, D.A.S.P.; writing—original draft preparation, D.A.S.P. and M.A.D.N.W.; writing—review and editing, K.A.A.G.; supervision, K.A.A.G.; project administration, K.A.A.G. All authors have read and agreed to the published version of the manuscript.

Funding: This research received no external funding.

Institutional Review Board Statement: Not applicable.

Informed Consent Statement: Not applicable.

Data Availability Statement: All the relevant data already included in the paper.

Conflicts of Interest: The authors declare no conflict of interest.

\section{References}

1. The World Economic Forum. The Future of Jobs Report 2020. 2020. Available online: https://www.weforum.org/reports/thefuture-of-jobs-report-2020 (accessed on 20 April 2021).

2. Eby, L.T.; Rhodes, J.E.; Allen, T.D. Definition and Evolution of Mentoring. In The Blackwell Handbook of Mentoring; Blackwell Publishing: Hoboken, NJ, USA, 2007; pp. 7-20.

3. Taruru, I.; Keriko, J.M.; Ombui, K.; Karanja, K.; Ondabu, I. Effects of coaching programmes on employee performance in business process outsourcing subsector of Nairobi city county, Kenya. Int. J. Sci. Res. Publ. 2015, 5, 6-24.

4. Dean, D. Getting the most out of your mentoring relationships. Mentor. Acad. Ind. 2009, 3, 3-5.

5. Hakro, A.N.; Mathew, P. Coaching and mentoring in higher education institutions: A case study in Oman. Int. J. Mentor. Coach. Educ. 2020, 9, 307-322. [CrossRef]

6. Robinson, C.E. Academic/Success Coaching: A Description of an Emerging Field in Higher Education. Ph.D. Thesis, University of South Carolina, Columbia, SC, USA, 2015. Available online: https://scholarcommons.sc.edu/etd/3148 (accessed on 30 April 2021).

7. Ali, Z.B.M.; Wahi, W.; Yamat, H. A Review of Teacher Coaching and Mentoring Approach. Int. J. Acad. Res. Bus. Soc. Sci. 2018, 8, 504-524. [CrossRef]

8. Devine, M.; Meyers, R.; Houssemand, C. How can Coaching Make a Positive Impact Within Educational Settings? Procedia Soc. Behav. Sci. 2013, 93, 1382-1389. [CrossRef]

9. Lancer, N.; Clutterbuck, D.; Megginson, D. Techniques for Coaching and Mentoring, 2nd ed.; Routledge: London, UK, 2016.

10. Capstick, M.K.; Harrell-Williams, L.M.; Cockrum, C.D.; West, S.L. Exploring the Effectiveness of Academic Coaching for Academically At-Risk College Students. Altern. High. Educ. 2019, 44, 219-231. [CrossRef]

11. Eleyan, D.; Eleyan, A. Coaching, Tutoring and Mentoring in the Higher Education as a solution to retain students in their major and help them achieve success. In Proceedings of the International Arab Conference on Quality Assurance in Higher Education (IACQA), Zarqa University, Zarqa, Jordan, 10-12 May 2011.

12. Carmel, R.G.; Paul, M.W. Mentoring and coaching in academia: Reflections on a mentoring/coaching relationship. Policy Futur. Educ. 2015, 13, 479-491. [CrossRef]

13. Knippelmeyer, S.A.; Torraco, R.J. Mentoring as a Developmental Tool for Higher Education. In Proceedings of the Academy of Human Resource Development International Research Conference in the Americas, Indianapolis, IN, USA, 28 February4 March 2007.

14. Leidenfrost, B.; Strassnig, B.; Schütz, M.; Carbon, C.C.; Schabmann, A. The Impact of Peer Mentoring on Mentee Academic Performance: Is Any Mentoring Style Better than No Mentoring at All? Int. J. Teach. Learn. High. Educ. 2014, 26, 102-111.

15. Abugre, J.B.; Kpinpuo, S.D. Determinants of Academic Mentoring in Higher Education: Evidence from a Research University. Educ. Process. Int. J. 2017, 6, 20-36. [CrossRef]

16. Artino, A.R., Jr.; Stephens, J. Academic motivation and self-regulation: A comparative analysis of undergraduate and graduate students learning online. Internet High. Educ. 2009, 12, 146-151. [CrossRef]

17. Omar, N.D.; Hassan, H.; Atan, H. Student Engagement in Online Learning: Learners Attitude toward E-Mentoring. Procedia Soc. Behav. Sci. 2012, 67, 464-475. [CrossRef]

18. Hiltz, S.R.; Turoff, M. Education goes digital: The evolution of online learning and the revolution in higher education. Commun. ACM 2005, 48, 59-64. [CrossRef]

19. Yang, Y.; Lin, N.C. Internet perceptions, online participation and language learning in Moodle forums: A case study on nursing students in Taiwan. Procedia Soc. Behav. Sci. 2010, 2, 2647-2651. [CrossRef]

20. Mondol, S.; Mohiuddin, M.G. Confronting Covid-19 with a Paradigm Shift in Teaching and Learning: A Study on Online Classes. Int. J. Soc. Polit. Econ. Res. 2020, 7, 231-247. [CrossRef] 
21. Pyeatt, M.D. The Relationship between Mentoring and Retention in Ministry. Ph.D. Thesis, The Ohio State University, Columbus, OH, USA, 2006; pp. 57-76.

22. Russell, S.H.; Hancock, M.P.; McCullough, J. The Pipeline: Benefits of Undergraduate Research Experiences. Science 2007, 316, 548-549. [CrossRef] [PubMed]

23. Hussain, S.; Tirmizi, S.M.; Mutahir, H. An Innovative Mentorship Behavior Model Imperative for Sustainable Higher Education. Int. J. Innov. Creat. Change 2021, 15, 335-349.

24. Ishak, N.A.; Mohtar, N.M.; Adin, I.S.; Haron, H. Strengthening Employee Performance: A Case Study of Maybank Berhad. Int. J. Acad. Res. Bus. Soc. Sci. 2017, 7, 2222. [CrossRef]

25. Neupane, R. Effects of Coaching and Mentoring on Employee Performance in the UK Hotel Industry. Int. J. Soc. Sci. Manag. 2015, 2, 123-138. [CrossRef]

26. Jyoti, J.; Sharma, P. Impact of Mentoring Functions on Career Development: Moderating Role of Mentoring Culture and Mentoring Structure. Glob. Bus. Rev. 2015, 16, 700-718. [CrossRef]

27. Okoye, K.; Hosseini, S.; Arrona-Palacios, A.; Escamilla, J. Impact of Educational Coaching Programs and Mentoring Services on Users' Perception and Preferences: A Qualitative and Quantitative Approach. IEEE Access 2021, 9, 48105-48120. [CrossRef]

28. Noufou, O.; Rezania, D.; Hossain, M. Measuring and exploring factors affecting students' willingness to engage in peer mentoring. Int. J. Mentor. Coach. Educ. 2014, 3, 141-157. [CrossRef]

29. Ragins, B.R.; Cotton, J.L.; Miller, J.S. Marginal mentoring: The effects of type of mentor, quality of relationship, and program design on work and career attitudes. Acad. Manag. J. 2000, 43, 1177-1194. 